\title{
Potential of a Two Motor Concept for Electric Vehicles with Respect to Its Interaction with the Air Conditioning Unit
}

\author{
Sigle, Sebastian \\ Institute of Vehicle Concepts \\ German Aerospace Center (DLR) \\ Stuttgart, Germany \\ Sebastian.Sigle@dlr.de
}

\author{
Dr. Schier, Michael \\ Institute of Vehicle Concepts \\ German Aerospace Center (DLR) \\ Stuttgart, Germany \\ Michael.Schier@dlr.de
}

\begin{abstract}
A common approach to enhance the overall efficiency of an electric driven vehicle is to use a double motor concept. In the hereby presented research project TIOM (Two in one motor) two different electric motors are used for traction and the compressor of the air conditioning (AC) system. The main research questions in the following paper are first which operation scenario fits best for this system and second if the developed operation strategy leads to higher efficiencies. For this purpose a simulation model of the vehicle including the $\mathrm{AC}$ circuit was built in Dymola. The model contains a strategy that can select between ten different operation modes for the two motors based on the efficiencies of the motors, the torque requirements, the rotation speed of the wheel and the rotation speed range of the $\mathrm{AC}$ compressor. The chosen operation scenarios are four driving cycles: the New European Driving Cycle (NEDC), the Worldwide harmonized Light vehicles Test Cycle (WLTC) and two real driving cycles, a regional cycle and a motorway cycle. The simulation also distinguishes between operation with activated and deactivated $\mathrm{AC}$ circuit. As a result the energy consumption in the different scenarios is evaluated and compared to a vehicle with a conventional motor concept with separated motors for the traction and $\mathrm{AC}$ circuit.
\end{abstract}

Keywords-energy, highly integrated drives, two in one motor concepts, simulation, Dymola, Modelica, real drive cycles

\section{INTRODUCTION}

The motivation and the basic idea of the TIOM concept is the integration of an air conditioning compressor into an electric drive, which was shown in [1] and [2]. In Figure 1 the current topology of the TIOM concept for a typical battery electric vehicle (BEV) containing two motors on one common shaft for traction, the AC compressor and the related power electronics (PE) is compared to a conventional system with two separate motors.

Two clutches allow to engage or disengage the two motors from the shaft. One motor (EM I) has a higher power rating than the other (EM II) and so the idea behind it is to operate every motor in its best efficiency point, depending on the applied load. Also a "Boost mode" that uses both motors together is considered.

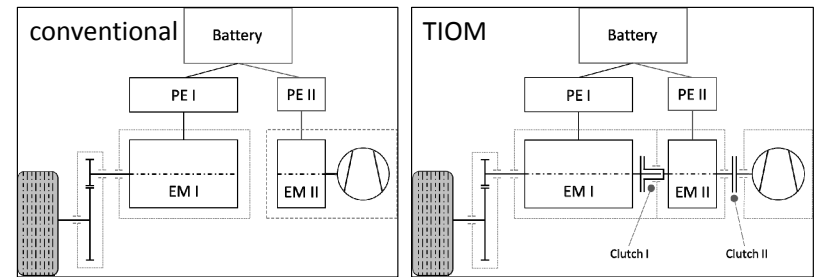

Fig. 1: Drivetrain topology of a BEV using the TIOM concept compared to a conventional drivetrain

Therefore both motors, the drive shaft and the compressor of the AC circuit can be coupled in different ways by using two clutches.

A basic electric design of the two motors was already done in [2]. Therefore two basic operation modes have been used to determine the energy reductions of this concept without respect to the $\mathrm{AC}$ circuit. In this paper an $\mathrm{AC}$ circuit with a compressor is modelled and included into a vehicle model. Also, multiple operation modes are developed and evaluated regarding energy efficiency.

\section{OPERATION SCENARIOS}

\section{A. Selecting the driving cycles}

For the evaluation of energy reduction effects it is common to determine the energy consumption in standard driving cycles. They are often used to compare different vehicles or technologies in the same cycle. Therefore synthetic cycles like the NEDC as defined in [3] are used.

This cycle consists of phases with constant acceleration, deceleration and constant velocity. Other cycles are defined in the Worldwide harmonized Light vehicles Test Procedure (WLTP) as described in [4]. These cycles are assigned to certain vehicle types and try to represent a more realistic driving behavior. For this paper the cycle WLTC $3 \mathrm{~b}$ was chosen. Though these cycles try to include several operation conditions such as motorway, urban areas and sub-urban areas, and vary in different velocities and acceleration and deceleration characteristics. 


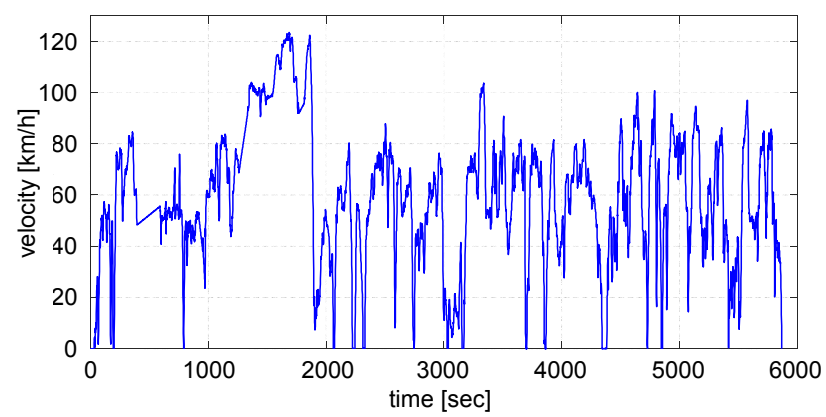

Fig. 2: Velocity profile of the cycle Stuttgart - Lampoldshausen, regional

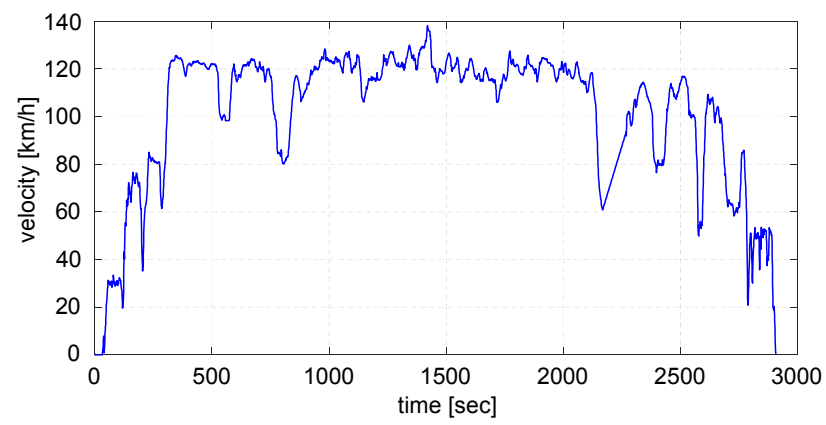

Fig. 3: Velocity profile of the cycle Lampoldshausen - Stuttgart, motorway

For the work presented in this paper it was essential to evaluate the TIOM concept and the later in this paper described operation modes in different operation conditions.

Therefore two real driving cycles are used, that have been recorded with integrated measurement equipment on different journeys between the DLR locations in Stuttgart (ST) and Lampoldshausen (LA). For the journey from Stuttgart to Lampoldshausen regional roads have been used as introduced in [6]. The velocity profile is shown in Figure 2. On the journey back the motorway was used, the corresponding velocity profile is shown in Figure 3. The altitude difference between ST and LA is $-192 \mathrm{~m}$.

In Table 1 the cycles are compared based on characteristic parameters. It is quite obvious that the main differences are the average velocity and the maximum acceleration, which are higher in the real driving cycles. But also the time in idle mode is different; it is much lower in the regional and motorway cycle than in the standard cycles. This is quite important, as even in standstill times the motor for the AC compressor has to run.

TABLE I: PARAMETERS OF THE USED DRIVE CYCLES

\begin{tabular}{|c|c|c|c|c|}
\hline \multirow{2}{*}{ Parameter } & \multicolumn{4}{|c|}{ Drive Cycles } \\
\cline { 2 - 5 } & NEDC & WLTC 3b & $\begin{array}{c}\text { ST-LA } \\
\text { regional }\end{array}$ & $\begin{array}{c}\text { LA-ST } \\
\text { motorway }\end{array}$ \\
\hline distance [km] & 10.99 & 23.26 & 96.14 & 81.77 \\
\hline duration [s] & 1,180 & 1,800 & 5,867 & 2,906 \\
\hline avg. velocity [km/h] & 33.5 & 46.5 & 60.7 & 102.46 \\
\hline max. velocity [km/h] & 120.0 & 131.3 & 123.5 & 138.2 \\
\hline max. acceleration [m/s $\left.{ }^{2}\right]$ & 1.04 & 1.67 & 3.24 & 2.32 \\
\hline idle time share [\%] & 23.7 & 12.6 & 2.67 & 1.14 \\
\hline
\end{tabular}

\section{B. Definition of the operation modes}

Ten different operation modes have been defined for the system. In Figure 4 the operation modes for deactivated Air conditioning (AC off) is shown, that means that the AC compressor is always off and clutch II is opened. At "Off" every device is deactivated, which is the case at standstill with deactivated AC. "EM I" means, that only EM I is used for propulsion, analogous "EM II" means that only EM II is used. Within the mode "Boost" both motors are used.

Six modes are used for activated Air conditioning (AC on) with clutch II closed. These are illustrated in Figure 5. In "EM I+AC" EM I propels the wheel and the $\mathrm{AC}$ compressor. Analogous to that "EM II+AC" represents the mode with only EM II working. In "Boost+AC" booth motors run on the same shaft as the clutch I is closed.

Whereas in "SplitAC" clutch I is opened and EM I propels the wheel and EM II propels the AC compressor. In "RekupAC" none of the motors is working. The wheel is directly connected to the compressor. Hereby the kinetic energy is used to propel the AC compressor. The last mode is "Off $+\mathrm{AC}$ " wherein EM II only propels the $\mathrm{AC}$ compressor and the vehicle is in standstill.

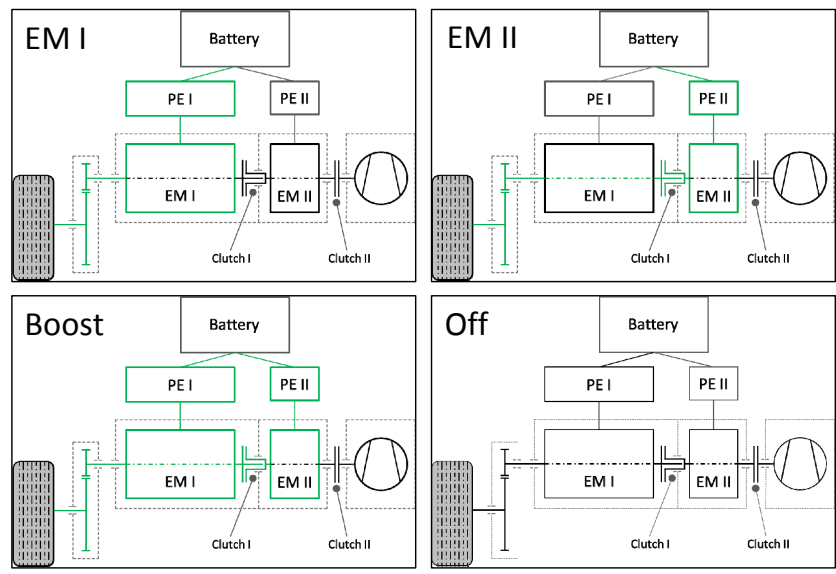

Fig. 4: Operation modes for $\mathrm{AC}$ off

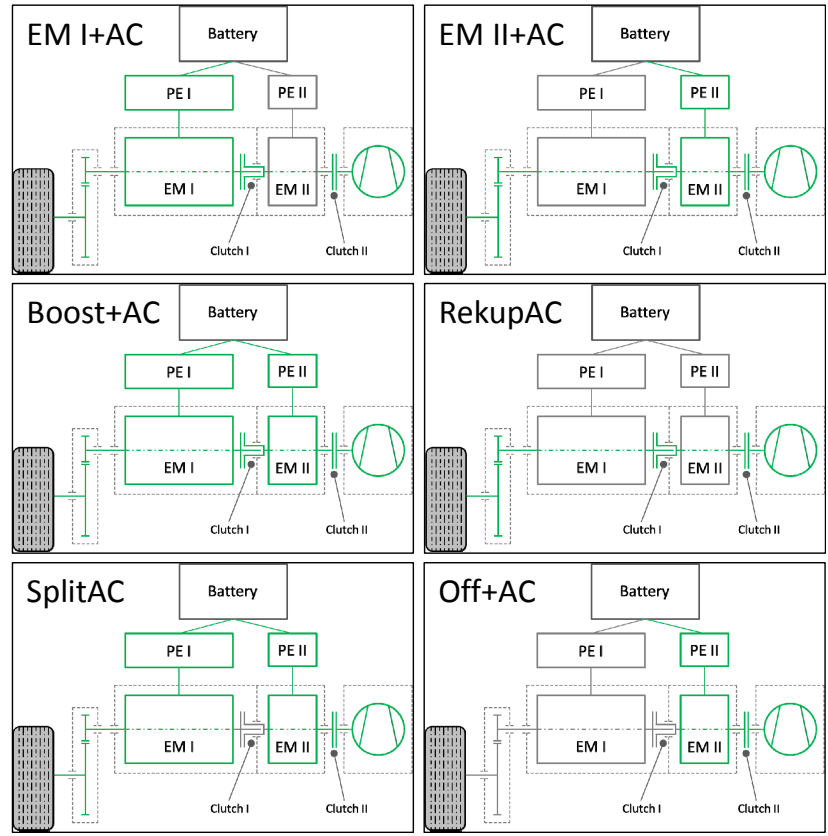

Fig. 5: Operation modes for AC on 


\section{MODELLING}

The modelling tool Dymola was used for the modelling and simulation, which is described in [7]. The model itself consists of two parts. One part is the model of the AC circuit, which was modeled using the commercially available AC library from Modelon, which is described in [8].

\section{A. The Modelling of the AC circuit}

The AC library contains several templates for automotive AC circuits that can be adapted to most of the use cases. The model is shown in Figure 6 and consists of a reciprocating compressor with variable displacement (1), a flat-tube evaporator in crossflow design (4), a flat-tube condenser in crossflow design (2), a thermo-static expansion valve (3), a refrigerant collector and connecting tubes with modeled pressure drop and a mechanical flange to the compressor (5). The chosen refrigerant is $\mathrm{R} 134 \mathrm{a}$ with a high pressure level of $17 \mathrm{bar}$ and a low pressure level of $3 \mathrm{bar}$ with subcooling of $2 \mathrm{~K}$ and overheating of $7 \mathrm{~K}$.

\section{B. The Modelling of the vehicle}

The AC circuit model is included into a vehicle model, which is based on the Alternative vehicles (AV) library. The connection is realized via a mechanical connection interface ( 5 in Figure 6) and a control Bus connector, which transmits the necessary status and control signals (yellow lines in the models). The control Bus is a standardized data interface for different Dymola libraries, which was developed with contribution of the DLR and Modelon as can be read in [9].

The AV library was developed by the DLR as can be read in [10] and is already commercially available. The model is a forward vehicle model that includes the longitudinal dynamics, the propulsion system with a battery electric drivetrain and the necessary control systems.

The vehicle model is illustrated in Figure 7 with the battery (1), EM I with $50 \mathrm{~kW}$ and corresponding power electronics (2), EM II with $10 \mathrm{~kW}$ and corresponding power electronics (3), clutch I (4), clutch II (5), the AC circuit model (6), the longitudinal dynamics (7), the driver model with drive cycle (8) and the control module (9).

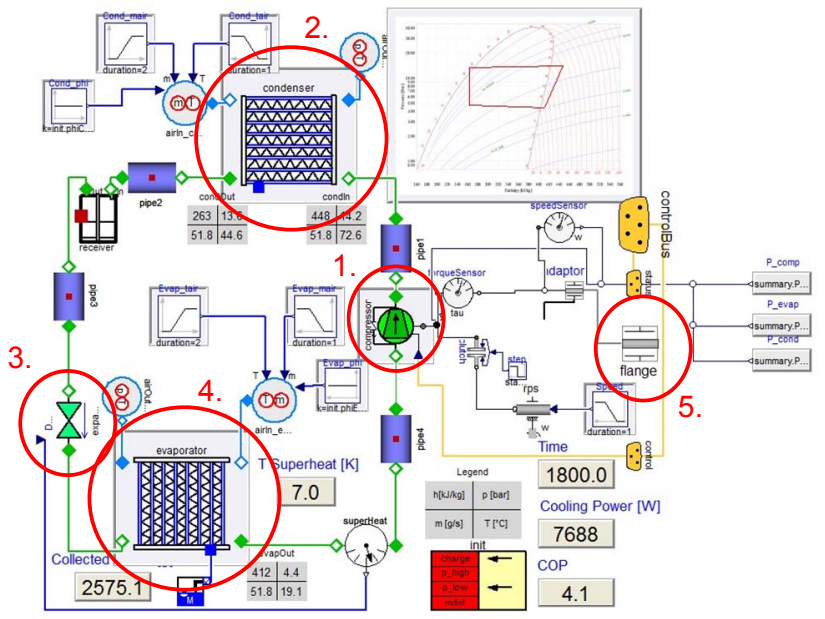

Fig. 6: AC circuit model based on AC library

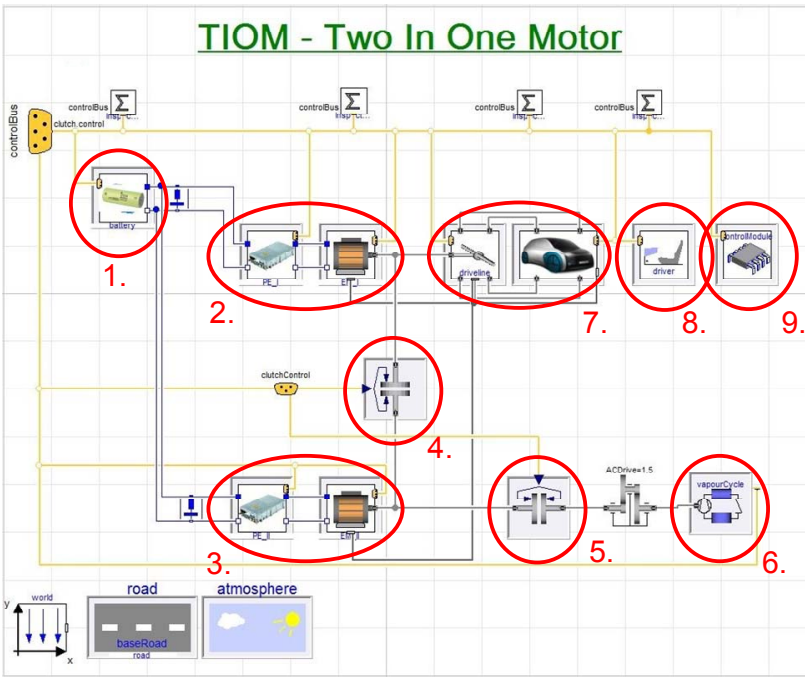

Fig. 7: Vehicle model based on AV library

Between clutch II and the AC circuit an additional gear was implemented to move the operating points of the $\mathrm{AC}$ compressor into an area with higher efficiencies.

According to [5] the mass of the vehicle was assigned to $1,600 \mathrm{~kg}$ with a front area of $2.18 \mathrm{~m}^{2}$, a drag coefficient of 0.29 and a rolling resistance coefficient of 0.015 .

\section{The Modelling of the operation strategy}

In the control module the status signals from the different submodels are evaluated and the control signals for the motors, the clutches and the compressor are generated. Also the operation strategy that determines the used operation mode is located there.

The control strategy is realized by using the state graph library, which distinguishes between the different operation modes. An implemented logic, based on the StateGraph Library, determines the mode based on the relevant parameters like the efficiencies of the motors, the maximum available power of the motors and the current load request.

Considering the overall efficiency of the vehicle, the optimum distribution of the load request on the two motors is determined. The efficiencies maps of the two used motors can be seen in Figure 8.

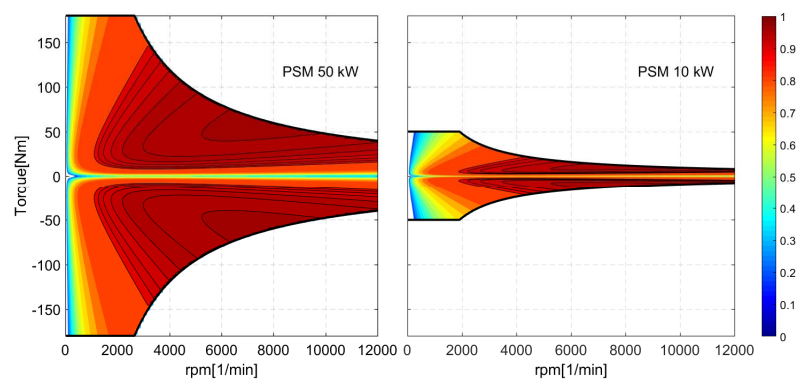

Fig. 8: Characteristic maps of the motors (left: EM I, right: EM II) 


\section{RESUlTS}

It was distinguished between vehicle operation with activated and deactivated AC circuit.

\section{A. Results for operation with deactivated AC circuit}

Regarding the operation with deactivated AC circuit the proportion of time spent in each mode is shown in Figure 9. The cycles NEDC and WLTC have the highest amount of idle time, which leads to a high percentage of the "Off" mode. Considering the real driving cycles the average power demand is higher and therefore the share of the mode "EM I" is greater. The only significant share of the boost mode occurs in the motorway cycle as the maximum power request is higher in this cycle.

To compare the TIOM concept with a conventional BEV drivetrain the simulation was run twice. Once with only mode "EM I" that represents the conventional drivetrain and once using all modes that represents the TIOM concept. Using the TIOM concept increases the average efficiency of each motor up to 2 percentage points and also increases the average overall efficiencies of the two motors as always the motor with the higher efficiency takes over. This yields to a reduction of the energy consumption for each cycle which is shown in Table 2. The highest energy reduction potential is given in the WLTC with $1.09 \%$ followed by the NEDC with $0.99 \%$ and the regional cycle with $0.95 \%$.

TABLE II: ENERGY CONSUMPTION FOR DIFFERENT CYCLES WITH DEACTIVATED AC CIRCUIT

\begin{tabular}{|c|c|c|c|c|}
\hline \multirow{2}{*}{ Power train } & \multicolumn{4}{|c|}{ Drive Cycles } \\
\cline { 2 - 5 } & NEDC & WLTC 3b & $\begin{array}{c}\text { ST-LA } \\
\text { regional }\end{array}$ & $\begin{array}{c}\text { LA-ST } \\
\text { motorway }\end{array}$ \\
\hline $\begin{array}{c}\text { conventional } \\
{[\mathrm{kWh} / 100 \mathrm{~km}]}\end{array}$ & 11.88 & 13.62 & 12.22 & 19.45 \\
\hline $\begin{array}{c}\text { TIOM } \\
{[\mathrm{kWh} / 100 \mathrm{~km}]}\end{array}$ & 11.76 & 13.47 & 12.10 & 19.35 \\
\hline reduction [\%] & 0.99 & 1.09 & 0.95 & 0.50 \\
\hline
\end{tabular}

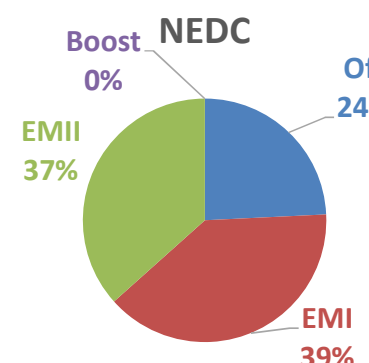

$39 \%$

\section{ST-LA REGIONAL}

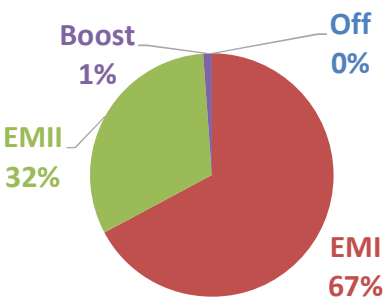

\section{LA-ST MOTORWAY}

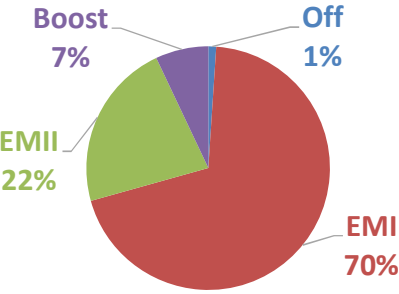

\section{B. Results for operation with deactivated AC circuit}

With activated AC circuit the situation is different. The proportion of time spent in each mode is visualized in Figure 10 . The "Off $+\mathrm{AC}$ " mode is mostly used in the cycles NEDC and WLTC.

The reason for that is the high amount of idle times, wherein EM II has to propel the AC circuit to ensure climatic comfort inside the vehicle. The Boost mode has no significant share, even in the motorway cycle.

A significant role plays the mode "SplitAC". This mode represents the conventional topology with one motor for traction and one motor for the compressor of the $\mathrm{AC}$ circuit.

The main disadvantage is that it is not possible to use the kinetic energy from the wheels directly for the compressor when the vehicle is decelerating. It's also not possible to use the second motor for the Boost mode.

The reason for that is visualized exemplarily on the regional cycle in Figure 11. There the operating points of both motors are shown dependent on the requested rotations and torque. The working range of the $\mathrm{AC}$ compressor is limited by the rotations between 1,000 and 8,000 revolutions per minute. This correlates with $14 \mathrm{~km} / \mathrm{h}$ and $95 \mathrm{~km} / \mathrm{h}$.

This means that below and above these limits it is not possible to have the wheel and the compressor on the same shaft. Therefore "SplitAC"-mode is used and EM I propels the wheel as EM II propels the AC compressor. These operating points mainly occur in the motorway cycle as velocities over $95 \mathrm{~km} / \mathrm{h}$ make up the majority.

The lack of the Boost mode also results in lower velocities in some demanding areas with velocities over $95 \mathrm{~km} / \mathrm{h}$ on the cycle. There the actual velocity could not meet the requested velocity.

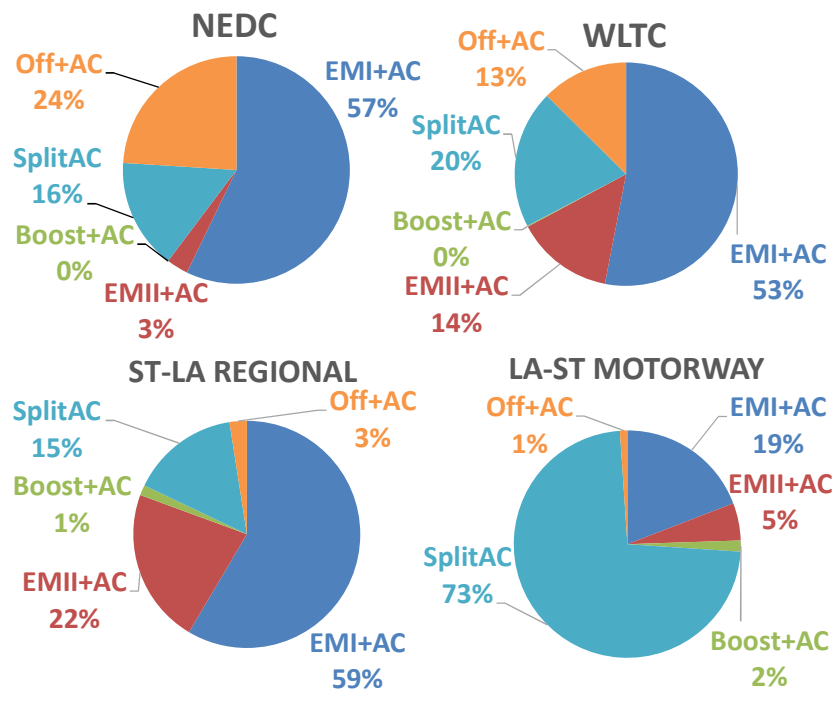

Fig. 10: Mode shares with activated AC circuit 


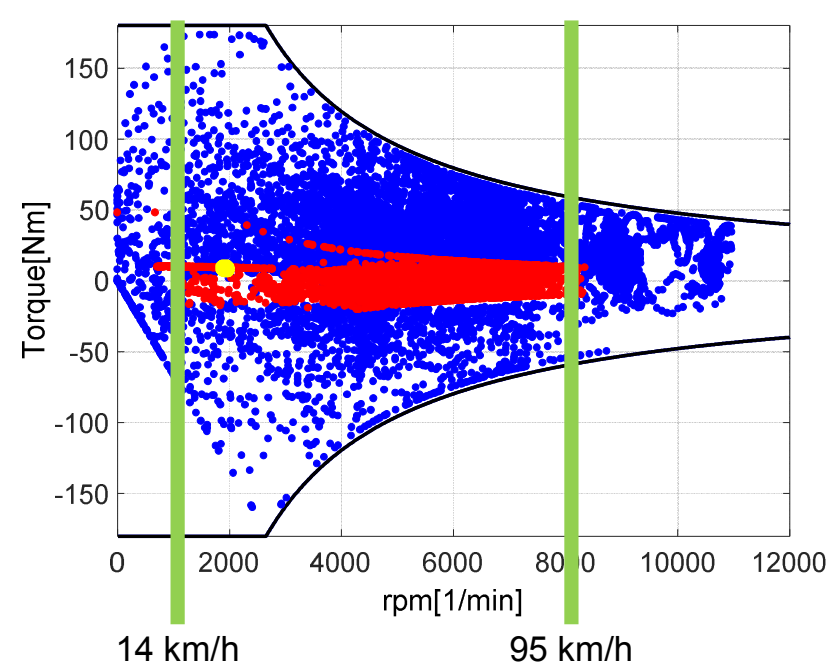

Fig. 11: Operating points for the cycle ST-LA regional with activated AC circuit (blue: EM I, red: EM II)

Again the simulation was run twice, once with the mode "SplitAC" which represents the conventional topology and once with all modes. In the first step the energy consumption was higher in every case using the TIOM concept. This was caused by the fact that the applied compressor is not adjustable. In this case the shaft of the compressor is often times directly connected to the wheels and is therefore delivering more cooling power than in "SplitAC"-mode.

Therefore the amount of electric energy that is additionally consumed by the compressor compared to the "SplitAC"-mode is subtracted from the energy consumption value when using all modes.

Using all modes the average efficiency of each motor increases in every cycle, as always the motor with the higher efficiency takes over. Also the overall efficiency in every cycle increases. This yields to a reduction of the energy consumption for each cycle which is shown in Table 3 . The reduction in each cycle is higher than in the case with deactivated AC circuit despite the motorway cycle.

There the high share of the mode "SplitAC" avoids a better efficiency and leads to a low energy reduction of only $0.25 \%$, compared to $0.50 \%$ in the cycle with deactivated AC circuit.

TABLE III: ENERGY CONSUMPTION FOR DIFFERENT CYCLES WITH ACTIVATED AC CIRCUIT

\begin{tabular}{|c|c|c|c|c|}
\hline \multirow{2}{*}{ Power train } & NEDC & WLTC $3 \boldsymbol{b}$ & $\begin{array}{c}\text { ST-LA } \\
\text { regional }\end{array}$ & $\begin{array}{c}\text { LA-ST } \\
\text { motorway }\end{array}$ \\
\cline { 2 - 5 } & 18.21 & 18.17 & 15.81 & 21.54 \\
\hline $\begin{array}{c}\text { conventional } \\
{[\mathrm{kWh} / 100 \mathrm{~km}]}\end{array}$ & 17.89 & 17.84 & 15.46 & 21.49 \\
\hline $\begin{array}{c}\mathrm{TIOM} \\
{[\mathrm{kWh} / 100 \mathrm{~km}]}\end{array}$ & 1.75 & 1.81 & 2.22 & 0.25 \\
\hline reduction [\%] & & &
\end{tabular}

\section{CONCLUSIONS}

In addition to further works an $\mathrm{AC}$ circuit was also considered and integrated in the vehicle model together with an appropriate operation strategy. The results of the simulation demonstrate that the TIOM concept is able to achieve a reduction of up to $2.2 \%$ of the energy consumption in a real drive cycle with the introduced operation strategy.

The energy reduction potential is mostly even higher when considering the AC circuit. The energy reduction potential differs from cycle to cycle. It is obvious that the reduction is higher in cycles with moderate velocities which indicate that this concept fits best in urban applications. The reason for that is the climatic compressor, which is not applicable for all operation conditions especially on high and very low velocities. An adjustable compressor could yield to higher overall efficiencies.

\section{ACKNOWLEDGMENT}

The authors would like to thank Mr. Christof Pfitzner for his helpful work in this paper presented topic and results. The research presented within this paper is supported by the German federal ministry for Economic Affairs and Energy.

\section{REFERENCES}

[1] Kumar, Satheesh und Schier, Michael (2014) Increasing efficiency of ecological vehicles by integrating auxiliary units directly to the driven shaft. International Conference on Ecological Vehicles and Renewable Energies, 25.-27.Mär. 2014, Monte Carlo.

[2] Schier, M.; Kumar, S.: Design of a 2 in 1 Motor to increase the Efficiency of Electric Vehicles, International Conference on Ecological Vehicles and Renewable Energies EVER15, Monte Carlo, 29.03.-02.04.15, Monaco, 2015

[3] Regulation No 83 of the Economic Commission for Europe of the United Nations (UNECE) - Uniform provisions concerning the approval of vehicles with regard to the emission of pollutants according to engine fuel requirements [2015/1038]

[4] Tutuianu, M., Marotta, A., Steven, H., Ericsson, E., Haniu, T., Ichikawa, N., \& Ishii, H. (2013). Development of a World-wide Worldwide harmonized Light duty driving Test Cycle (WLTC). Technical Report.

[5] Hubner, M.; Schier, M.; Kevlishvili, N.; Dietz, A.; Hörlin, S.: Methodical Approach for designing electric propulson systems containing two motors, International Conference on Ecological Vehicles and Renewable Energies (EVER 17), 11.-13.04.17, Monte Carlo, Monaco

[6] Dickinson, Dave und Nasri, Mounir (2014) Range Extender Vehicle Concept Based on High Temperature Polymer Electrolyte Membrane Fuel Cell. In: IEEE Xplore. 2014 Ninth International Conference on Ecological Vehicles and Renewable Energies (EVER), 25.-27. März 2014, Monaco, Frankreich.

[7] Dempsey, Mike. Dymola for multi-engineering modelling and simulation. In: 2006 IEEE Vehicle Power and Propulsion Conference. IEEE, 2006. S. 1-6.

[8] Tummescheit, Hubertus; Eborn, Jonas; Prölss, Katrin. Airconditioning - a Modelica library for dynamic simulation of AC systems. In: 4th International Modelica Conference. 2005.

[9] Dempsey, Mike und Gäfvert, Magnus und Harman, Peter und Kral, Christian und Otter, Martin und Treffinger, Peter (2006) Coordinated automotive libraries for vehicle system modelling. In: Proceedings, Seiten 33-41. 5th International Modelica Conference, 2006-09-04 2006-09-05, Wien.

[10] Hülsebusch, Dirk und Ungethüm, Jörg und Braig, Thomas und Dittus, Holger: Multidisziplinäre Simulation von Fahrzeugen. Automobiltechnische Zeitschrift: ATZ (111), pages 772-779, Springer, 2009 